\title{
A comparison of sensory loss tests and histopathology in the diagnosis of leprosy
}

\author{
J M PONNIGHAUS* \& P E M FINE \\ *Lepra Evaluation Project, PO Box 46, Chilumba, Malawi; †Lon- \\ don School of Hygiene and Tropical Medicine, Keppel Street, \\ London WC1
}

\section{Accepted for publication 15 November 1988}

\begin{abstract}
Summary Three different sensory loss tests, for anaesthesia to light touch, for diminished pain sensation and for loss of thermosensation, were compared with histopathological examination results in the diagnosis of suspected tuberculoid leprosy in 120 individuals with 126 lesions. Though none of the 3 tests used in this study was found to be strikingly superior to any of the others, the results indicate potentially important differences in their usefulness in different subgroups of suspected patients. The methodological problems inherent in such studies are discussed.
\end{abstract}

\section{Introduction}

Different forms of peripheral sensory loss are well recognized consequences of infection with Mycobacterium leprae. Anaesthesia is generally cited as one of the cardinal signs of leprosy, and its assessment - in particular anaesthesia to light touch — is part of the routine clinical examination for the disease. In addition some workers have recommended the use of tests for diminished pain sensation and for loss of thermal sensation in the diagnosis of leprosy. ${ }^{2,3}$

Testing for sensory loss is of ten difficult, in particular under field conditions. The individuals being tested must both understand and co-operate in the procedure. If the sensory loss is not extensive, considerable time, patience and scepticism may be required of the tester. Given the importance and difficulty of such tests in leprosy work, it is of interest to assess their usefulness in practice. In particular we wish to know their validity in terms of sensitivity (the proportion of 'true' leprosy lesions which are correctly identified as showing sensory loss), specificity (the proportion of lesions not due to $M$. leprae which do not show sensory loss), and their repeatability in the hands of different workers.

There is little literature assessing these tests. The only relevant publication known to us is a study comparing the repeatability of 4 different sensory loss (light touch, static 2-point discrimination, tuning fork and pinprick tests) and voluntary muscle tests in a group of 20 tuberculoid leprosy patients with established nerve lesions. ${ }^{4}$ The author suggested that the light touch test was more sensitive than the other 3 sensory loss tests. She reported no significant difference between sensory tests performed by the same observer at intervals of 2 weeks. No values for the sensitivity of the sensory tests were given. 
This lack of literature on this subject is attributable in part to a problem which confronts all studies of diagnostic tools in leprosy - the absence of an appropriate reference test. The sensitivity and specificity of any diagnostic tool should in theory be calculated with reference to a series of individuals whose true diagnostic status is known with reasonable certainty on the basis of some alternative diagnostic tests. ${ }^{5}$ Such ref erence information is difficult to obtain in leprosy, in particular for those 'early' paucibacillary lesions for which the field diagnosis is difficult and for which improvements in diagnostic methods are most needed.

Recognition of the problems of sensory loss testing has led to interest in a portable thermal sensation tester (Speyside Electronics, St Aethans, Burghead, Moray, UK). Such a device might prove usef ul in leprosy diagnosis for two reasons. First, it can provide a fixed standarized stimulus. Second, in so far as thermal and pain sensations a re dependent upon non-myelinated fibres, whereas touch sensations are dependent largely upon myelinated fibres, the ability to discriminate temperature might be lost before the touch sensation is impaired. ${ }^{6}$

This paper reports findings in assessing standard measures of anaesthesia to light touch, of diminished pain sensation and of diminished thermal sensation in the diagnosis of leprosy in the LEPRA Evaluation Project in Northern Malawi.

\section{Methods}

Three different sensory losses were applied to 120 individuals identified by paramedical workers as leprosy suspects in the course of a total population survey in Karonga District, Northern Malawi. ${ }^{7}$ All 120 individuals were suspected to have paucibacillary leprosy, usually with unknown time of onset and presumably in an early stage of the evolution of tuberculoid disease. Only 1 individual already had typical peripheral nerve damage of very recent onset, but 6 individuals were suspected relapses (or re-infections?) as they had received antileprosy treatment before. The 120 individuals do not represent a selected group but were found consecutively during the population survey. The following 3 tests for sensory loss were carried out by the medical officer (JMP):

1 Loss of appreciation of light touch: The individuals were shown cotton wool which was rolled to a point, and the threshhold was tested at which they could just still feel the wool's touch on normal skin in the vicinity of the lesion and in particular on normal skin in an area on the body opposite to the suspected lesion. Af ter the test had been explained, the individual's eyes were shielded so that he or she could not see the examiner's hand. Care was always taken to compare the lesion with an area of similar basic sensitivity to light touch ${ }^{8}$ After repeatedly touching the suspected lesion and comparable normal skin it was concluded that there was anaesthesia to light touch if the individuals always noticed the touch and pointed to it on the normal skin but repeatedly missed touches on the lesion. Misreference, a failure to indicate the exact location touched by the cotton wool, was not interpreted as a sign of anaesthesia to light touch.

2 Loss of thermosensation: The hand-held penlight battery-powered device, ${ }^{9}$ which has a 'cold' (=environmental temperature) end and a 'hot' $\left(=40^{\circ} \mathrm{C}\right)$ end, was demonstrated on normal skin until it was clear that the individual understood the procedure. Early in the investigation it was recognized that the thermosensation test had to be carried out in the shade. Otherwise the 'cold' end would get just as warm as the 'hot' end and it became impossible to discriminate between the two. Loss of thermosensation was recorded as present if individuals could not discriminate between hot and cold within the lesions but did so on normal skin in the vicinity of the lesion and on normal skin in an area on the opposite part of the body.

3 Diminished pain sensation: This was tested by pricking lightly with the sharp end of a 26-gauge needle. It involved explanation of the concept of 'more' and 'less' painful, a concept which is very difficult to translate into the local languages (Kyangonde and Chitumbuka, e.g. a 'faster' runner has to be translated as 'the first to arrive'). On a few occasions it was not possible to perform this test 
despite patient efforts by the paramedical worker (Leprosy Control Assistant) to explain it. Once understood, pain sensation was compared by pricking the lesion and normal skin in random order. A marked reduction of pain sensation was sometimes indicated by the absence of a withdrawal reflex. However, in recording results, such visible evidence was not distinguished from diminished pain sensation according to the individual's answers as to whether there was 'less' pain sensation in the lesion.

All tests were perf ormed with the suspects closing their eyes or having eyes shielded with a pad of paper. Suspects and observer were always seated during the testing unless the site of the lesion(s) made that impractical. In general the test for diminished pain sensation was performed last because it was the most unpleasant and difficult to understand of the three.

The results of all 3 tests were recorded as: Y, Yes, loss of . .; N. No, loss of . .; D, doubtful loss of ...; and $\mathrm{U} / \mathrm{T}$, procedure not understood or technically unsatisfactory.

After performing these tests 1 or more 4-mm punch biopsies were taken under local anaesthesia and processed as described elsewhere. ${ }^{10}$ The size and site ${ }^{11}$ of each lesion which was tested and from which a biopsy was taken were entered into an examination form (LEP Detailed Examination Form). ${ }^{7}$ The histopathologist was not aware of this study while it was in progress and the biopsy specimens were thus processed and examined in the routine fashion established for the LEP as described elsewhere. ${ }^{10}$

For the purpose of this study the histopathology results are taken as the reference diagnosis against which the sensitivity and specificity of the sensory testing are measured. We are aware that this method is not entirely satisfactory in so far as the histopathological diagnosis cannot be assumed to be invariably correct. ${ }^{12}$ On the other hand, the histopathological results may reasonably be considered more accurate than sensory testing results, in particular if the result of only 1 test is compared with the histopathology result. The methodology becomes more questionable if the results of 2 or 3 tests contrast with the histopathology result. We shall discuss this issue further after presenting our data.

Biopsy results were graded as follows: 1a, 'leprosy confirmed beyond reasonable doubt'; $2 \mathrm{~b}$, 'pathological and possibly due to leprosy but lacking specific diagnostic criteria'; and 3a, $3 \mathrm{~b}$ or 4, no evidence of leprosy (3a, 'definitely pathological but completely nonspecific'; 3b, 'normal or near normal tissue'; and 4, 'pathological but indicative of a specific disease other than leprosy'). ${ }^{10,12}$

\section{Results}

During the course of this study a total of 126 lesions were tested and biopsied in 120 individuals with suspected tuberculoid leprosy. The results of testing for anaesthesia to light touch are shown in Table 1. All individuals understood the procedure and there were no technically unsatisfactory results. The results were considered doubtful in 5 lesions.

The sensitivity of testing for anaesthesia to light touch is calculated as the percentage of histopathologically confirmed tuberculoid leprosy lesions (biopsy grading la) which were found to be anaesthetic. These were 32 out of 66 , and thus the sensitivity of testing for anaesthesia to light touch in this series was $48.5 \%$. The relative specificity of testing for anaesthesia to light touch is calculated as the percentage of 'lesions considered not due to leprosy' (biopsy grading 3a-4) in which no anaesthesia to light touch was found on single testing (at the time of taking the biopsy). There were 18 out of 25 , giving a relative specificity of testing for anaesthesia to light touch in this series of $72 \%$.

Table 1 also shows the results of testing for loss of thermosensation. Data on only 125 lesions are included, as one result was lost. The sensitivity of testing for loss of thermosensation can be calculated as $49 \cdot 2 \%(32 / 65)$. The relative specificity of the test in this series is $68 \%(17 / 25)$.

Table 1 further shows the results of testing for diminished pain sensation. Results are available for only 100 lesions because this test was added to the protocol only after the first 26 lesions had been 
Table 1. Anaesthesia to light touch, loss of thermosensation and diminished pain sensation test results in 120 individuals with suspected tuberculoid leprosy. Sensory loss results are recorded as Y (yes), N (no), D (doubtful) or $\mathrm{U} / \mathrm{T}$ (not understood or technically unsatisf actory)

\begin{tabular}{|c|c|c|c|c|c|c|}
\hline Biopsy results & $\mathrm{Y}$ & $\mathbf{N}$ & D & $\mathrm{U} / \mathrm{T}$ & $\begin{array}{c}\text { Total } \\
\text { number of } \\
\text { lesions }\end{array}$ & $\begin{array}{l}\chi^{2} \text { value excluding } \\
\mathrm{D} \text { and } \mathrm{U} / \mathrm{T} \text { results }\end{array}$ \\
\hline \multicolumn{7}{|c|}{ Anaesthesia to light touch } \\
\hline Leprosy certain & 32 & 31 & 3 & 0 & 66 & \\
\hline Possibly leprosy & 13 & 21 & 1 & 0 & 35 & \\
\hline No evidence of leprosy & 6 & 18 & 1 & 0 & 25 & \\
\hline Total & 51 & 70 & 5 & 0 & 126 & $4.98(p>0.05) \mathrm{NS}$ \\
\hline \multicolumn{7}{|c|}{ Loss of thermosensation } \\
\hline Leprosy certain & 32 & 26 & 0 & 7 & 65 & \\
\hline Possibly leprosy & 10 & 24 & 1 & 0 & 35 & \\
\hline No evidence of leprosy & 6 & 17 & 1 & 1 & 25 & \\
\hline Total & 48 & 67 & 2 & 8 & 125 & $8.76(p<0.05)$ \\
\hline \multicolumn{7}{|c|}{ Diminished pain sensation } \\
\hline Leprosy certain & 30 & 11 & 1 & 9 & 51 & \\
\hline Possibly leprosy & 8 & 16 & 0 & 1 & 25 & \\
\hline No evidence of leprosy & 7 & 12 & 1 & 4 & 24 & \\
\hline Total & 45 & 39 & 2 & 14 & 100 & $12.47(p<0.01)$ \\
\hline
\end{tabular}

tested for loss of appreciation of light touch and loss of thermosensation. The sensitivity and relative specificity of testing for diminished pain sensation were $58.8 \%$ and $50 \%$ respectively. The test was considered technically unsatisfactory or was not understood for 14 individuals.

The association between sensory tests giving a result of $\mathrm{Y}$ or $\mathrm{N}$ and biopsy result were analysed using a $\chi^{2}$ test ( 2 degrees of freedom). ${ }^{13}$ The $\chi^{2}$ and $p$ values are shown in Table 1 . This analysis reveals no statistically significant association between anaesthesia to light touch and biopsy result, some association between loss of thermosensation and biopsy status, and a highly significant association between diminished pain sensation and biopsy result.

The results are subdivided by age ( $<25$ versus $=$ or $>25$ years), sex and lesion site (face versus rest of body) in Table 2 . The most interesting finding in this analysis is that both the sensitivity and the relative specificity of all 3 tests were higher in individuals less than 25 years of age than in older individuals. Though they are consistent for all 3 tests, these differences in sensitivities and relative specificities between young and older individuals cannot be considered independent, and thus they fail to reach statistical significance at the $5 \%$ level.

In addition, it appears that for lesions on the 'rest of the body' the sensitivity and relative specificity may be slightly higher by testing for anaesthesia to light touch than by the other 2 tests.

For males testing for anaesthesia to light touch appeared slightly preferable while in females testing for loss of thermosensation seems the superior test. However neither of these differences is statistically significant.

Thus far the analysis has addressed the question whether any of the 3 tests had an advantage over the others. A further question is how usef ul it is for the clinician to use more than 1 test in order to arrive at a diagnosis in suspected tuberculoid lesions. To answer this we have analysed the results 
Table 2. Sensitivity and relative specificity of testing for anaesthesia to light touch, loss of thermosensation and diminished pain sensation by subgroup. The actual numbers of lesions are given in brackets.

\begin{tabular}{|c|c|c|}
\hline Subgroup & Sensitivity & Relative specificity \\
\hline & \multicolumn{2}{|c|}{ Anaesthesia to light touch } \\
\hline$<25$ years of age & $59 \cdot 1 \%(13 / 22)$ & $90 \cdot 1 \%(10 / 11)$ \\
\hline$=$ or $>25$ years of age & $43 \cdot 2 \%(19 / 44)$ & $57 \cdot 1 \%(8 / 14)$ \\
\hline Face & $15 \cdot 4 \%(2 / 13)$ & $100 \%(8 / 8)$ \\
\hline Rest of the body & $61 \cdot 2 \%(30 / 49)$ & $66 \cdot 7 \%(10 / 15)$ \\
\hline Males & $58 \cdot 3 \%(14 / 24)$ & $80 \%(12 / 15)$ \\
\hline Females & $46 \cdot 2 \%(18 / 39)$ & $66 \cdot 7 \%(6 / 9)$ \\
\hline \multirow[t]{2}{*}{ Total } & $48 \cdot 5 \%(32 / 66)$ & $72 \%(18 / 25)$ \\
\hline & \multicolumn{2}{|c|}{ Loss of thermosensation } \\
\hline$<25$ years of age & $59 \cdot 1 \%(13 / 22)$ & $90 \cdot 1 \%(10 / 11)$ \\
\hline$=$ or $>25$ years of age & $44 \cdot 2 \%(19 / 43)$ & $50 \%(7 / 14)$ \\
\hline Face & $46 \cdot 2 \%(6 / 13)$ & $87 \cdot 5 \%(7 / 8)$ \\
\hline Rest of the body & $50 \cdot 1 \%(26 / 51)$ & $56 \cdot 2 \%(9 / 16)$ \\
\hline Males & $41 \cdot 7 \%(10 / 24)$ & $66 \cdot 7 \%(10 / 15)$ \\
\hline Females & $53 \cdot 7 \%(22 / 41)$ & $70 \%(7 / 10)$ \\
\hline \multirow[t]{2}{*}{ Total } & $49 \cdot 2 \%(32 / 65)$ & $68 \%(17 / 25)$ \\
\hline & \multicolumn{2}{|c|}{ Diminished pain sensation } \\
\hline$<25$ years of age & $72 \cdot 2 \%(13 / 18)$ & $60 \%(6 / 10)$ \\
\hline$=$ or $>25$ years of age & $51 \cdot 6 \%(17 / 33)$ & $42 \cdot 9 \%(6 / 14)$ \\
\hline Face & $80 \%(8 / 10)$ & $42 \cdot 9 \%(3 / 7)$ \\
\hline Rest of the body & $55 \%(22 / 40)$ & $56 \cdot 2 \%(9 / 16)$ \\
\hline Males & $72 \cdot 2 \%(13 / 18)$ & $50 \%(7 / 14)$ \\
\hline Females & $51 \cdot 6 \%(17 / 33)$ & $50 \%(5 / 10)$ \\
\hline Total & $58 \cdot 8 \%(30 / 51)$ & $50 \%(12 / 24)$ \\
\hline
\end{tabular}

Table 3. Sensory test results for 75 lesions in which all results were either Y, 'loss of ....' or No, 'no loss of . . .' (excluding all lesions in which any sensory test result was $\mathrm{U} / \mathrm{T}$ or D).

\begin{tabular}{|c|c|c|c|c|c|c|c|c|c|}
\hline \multirow{3}{*}{$\begin{array}{l}\text { Test } \\
\text { Anaesthesia to light touch } \\
\text { Loss of thermosensation } \\
\text { Diminished pain sensation }\end{array}$} & \multicolumn{4}{|c|}{$\begin{array}{c}\text { Result } \\
\text { Yes }\end{array}$} & \multicolumn{4}{|c|}{$\begin{array}{c}\text { Result } \\
\text { No }\end{array}$} & \multirow[t]{2}{*}{ Total } \\
\hline & \multicolumn{2}{|c|}{ Yes } & \multicolumn{2}{|c|}{ No } & \multicolumn{2}{|c|}{ Yes } & \multicolumn{2}{|c|}{ No } & \\
\hline & Yes & No & Yes & No & Yes & No & Yes & No & \\
\hline \multicolumn{10}{|l|}{ Biopsy result } \\
\hline Leprosy certain & 8 & 1 & 5 & 3 & 9 & 2 & 4 & 3 & 35 \\
\hline Possibly leprosy & 1 & 1 & 5 & 3 & 2 & 2 & 0 & 9 & 23 \\
\hline No evidence of leprosy & 2 & 1 & 1 & 0 & 0 & 1 & 3 & 9 & 17 \\
\hline Total & 11 & 3 & 11 & 6 & 11 & 5 & 7 & 21 & 75 \\
\hline
\end{tabular}


Table 4. Sensitivity and relative specificity results for 17 individuals with at least one lesions in whom all three sensory test results were either ' $\mathrm{Y}$ ' or ' $\mathrm{N}$ '

\begin{tabular}{lcc}
$\begin{array}{l}\text { Number of } \\
\text { tests indicating } \\
\text { a sensory loss }\end{array}$ & Sensitivity & \multicolumn{1}{c}{$\begin{array}{c}\text { Relative } \\
\text { specificity }\end{array}$} \\
\hline 3 & $22 \cdot 2 \%(8 / 35)$ & $88 \cdot 2 \%(15 / 17)$ \\
At least 2 & $65 \cdot 7 \%(23 / 35)$ & $76 \cdot 4 \%(13 / 17)$ \\
At least 1 & $91 \cdot 4 \%(32 / 35)$ & $52 \cdot 9 \%(9 / 17)$ \\
\hline
\end{tabular}

in those individuals who understood all 3 tests and in whom there were no technically unsatisfactory or doubtful results. The test results of 75 lesions are included (Table 3). Two points deserve note in Table 3: (a), in 3 (14\%) out of 21 individuals who showed no evidence of sensory loss by any of the 3 tests the histopathologist found definite evidence of leprosy. In 2 of these 3 individuals the biopsy was taken from the face; and (b), in $2(18 \%)$ out of 11 individuals in whom the clinician found evidence of sensory loss with all 3 tests the histopathologist found no evidence of leprosy. While it would seem possible that the clinician was deceived, or deceived himself, in these two instances, they may represent false negative biopsy results. Since both individuals were started on antileprosy treatment because of the clinical findings, the question can not be resolved by repeat examination or biopsies.

The sensitivity and relative specificity of at least 1 recorded loss, of at least 2 recorded losses and of all 3 tests showing loss of appreciation of light touch, loss of thermosensation and diminished pain sensation respectively are presented in Table 4 . This reveals how requiring progressively more stringent criteria decreases the sensitivity but increases the specificity of the diagnostic procedure.

\section{Discussion}

Ideally, to examine the validity of a test, one needs to compare its results with those of a test which is both $100 \%$ sensitive and $100 \%$ specific. However, no such test is available in 'early' paucibacillary leprosy. The clinical certainty scale we developed includes anaesthesia to light touch as one of the findings to be considered and is therefore not suitable for reference purposes. ${ }^{14}$ We have therefore used histopathology as the reference criterion in this study. Though the true sensitivity of the histopathological diagnoses is unknown, we may reasonably assume that there were fewer false positive than false negative biopsies. This means that the sensitivity measures calculated in this study, which were based upon the histopathologically confirmed cases, are likely to be more accurate than are the specificity measures (given that we expect some 'true' leprosy cases to have escaped biopsy confirmation). For this reason we have used the phrase 'relative specificity' throughout this paper, to emphasize that the several tests are being measured with reference to biopsy information.

For an ideal study lesions should have been included in the study which were definitely not due to leprosy. However, no such lesions were available for both sensory testing and biopsy. Indeed, such a study would be difficult to arrange in so far as the clinician would be influenced by his perception of the lesion and his knowledge that sensory loss is associated with very few lesions except those due to leprosy.

The histopathologist was blind as far as the diminished pain sensation and thermosensation testing results were concerned, but information on the anaesthesia to light touch was occasionally communicated to him as part of the routine description of the lesions (which also usually contained a ref erence to the age and sex of the suspect and the site from which the biopsy was taken) ${ }^{10}$ There is 
however no evidence that the histopathologist was appreciably influenced by the clinical notes in assigning his biopsy certainty grade. ${ }^{12}$ The clinician did not know the biopsy results at the time of performing the sensory tests. On the other hand, the clinician was aware of the previous test's result when performing the second and third tests. This could have influenced him slightly, when in doubt. The only way to avoid this potential bias would be either to randomize the order of testing in different suspects or else to have each test performed independently by different clinicians.

In spite of these shortcomings in the design of this study we conclude that an observed sensory loss of some kind has to be treated with considerable caution in the diagnosis of 'early' tuberculoid leprosy.

The sensitivity and relative specificity of each of the tests as used in this study was approximately $60 \%$. None was found to be strikingly superior to any of the others. One might argue that the results indicate that testing anaesthesia to light touch is the least reliable of the three, since the association with the histopathological results is weakest for this test (Table 1). However, this is due to the fact that the $\chi^{2}$ test results are based on positive and negative results only, and exclude doubtful and technically unsatisfactory results. As the percentage of such results was highest for diminished pain sensation testing, the sensitivity and specificity figures are better indicators of the tests' overall usefulness than are the $\chi^{2}$ values.

In theory, the application of multiple tests can raise the sensitivity of the procedure. More than $91 \%$ of the histopathologically confirmed lesions showed sensory loss with at least one of the tests (Table 4). On the other hand, such a multiple test criterion was associated with a fall in relative specificity to only $53 \%$. We have discussed the relative importance of sensitivity and specificity in leprosy diagnoses in another publication. ${ }^{15}$

The tests may differ in their usefulness between certain subgroups. In particular, all 3 tests appeared to be more valid in younger than in older individuals (Table 2). One important consequence of such a result is that whenever the sensitivity and specificity of sensory tests are compared, for example between diff erent investigators or centres, the results should be related to the age of the individuals tested.

While the results of this study indicate potentially important differences in the usefulness of the test in different subgroups, a large investigation and more detailed analysis will be required to confirm these findings. We thus plan to expand this investigation in the future. In the short term we believe these preliminary results will be of interest to leprologists grappling with the difficult problem of diagnosing 'early' tuberculoid leprosy in the field.

\section{Acknowledgments}

The authors wish to thank Dr H Sansarricq, previously Chief Medical Officer, Leprosy, WHO for making the thermosensation tester available to us and for encouraging this study. Dr A C McDougall examined all the biopsy specimens. Basic funding for the Lepra Evaluation Project is provided by the British Leprosy Relief Association (LEPRA). The authors also wish to thank Nick Maine for help with the analysis.

\section{References}

1 Dharmendra. Leprosy, Vol 1. Bombay: Kothari Medical Publishing House, 1978; pp. 247-50.

2 Bryceson A, Pfaltzgraff RE. Leprosy, 2nd edn. Edinburgh. London and New York: Churchill Livingstone, 1979; p. 30.

3 Arnold HL Jr, Fasal P. Leprosy, Diagnosis and Management, 2nd edn. Springfield, Illinois, USA: Charles C Thomas, 1973; p. 38.

${ }^{4}$ Lewis S. Reproducibility of sensory testing and voluntary muscle testing in evaluating the treatment of acute neuritis in leprosy patients. Lepr Rev, 1983; 54: 23-30. 
5 MacMahon B, Pugh TF. Epidemiology, Principles and Methods, Boston: Little, Brown and Company, 1973; pp. 261-2.

${ }^{6}$ Srinivasan $\mathrm{H}$. What can we expect from thermal sense testing. Unpublished document prepared for Leprosy Unit, World Health Organization, Geneva, 1983.

7 Ponnighaus JM, Fine PE, Bliss L, Sliney IJ, Bradley JD, Rees RJW. The Lepra Evaluation Project (LEP), an epidemiological study of leprosy in Northern Malawi. 1 Methods. Lepr Rev, 1987; 58: 359-75.

8 Jamison DG. Sensitivity testing as a means of differentiating the various forms of leprosy found in Nigeria. Lepr Rev, 1969: 40: 17-20.

9 'New Devices' Medicine Digest, June 1984 Vol 10 No 6, page 60.

${ }^{10}$ McDougall AC, Ponnighaus JM, Fine PEM. The histopathological examination of skin biopsies from an epidemiological study of leprosy in Northern Malawi. Int J Le pr, 1987; 55: 88-98.

11 Boerrigter G. Grid system and body diagram for leprosy. Lepr Rev, 1983: 54: 115-18.

12 Fine PEM, Job CK, McDougall AC, Meyers WM, Ponnighaus JM. Comparability between histopathologists in the diagnosis and classification of leprosy. Int $J$ Lepr, 1986; 54: 614-25.

13 Bahn AK. Basic Medical Statistics. New York and London: Grune \& Stratton, 1972; pp. 63-78.

14 Ponnighaus JM, Fine PEM, Bliss L. Certainty levels in the diagnosis of leprosy. Int J Le pr, 1987; 55: 454-62.

15 Ponnighaus JM, Fine PEM. Sensitivity and specificity of the diagnosis, and the search for risk factors for leprosy. Trans $R$ Soc Trop Med Hyg, in press. 